\title{
White Commissure
}

National Cancer Institute

\section{Source}

National Cancer Institute. White Commissure. NCI Thesaurus. Code C33890.

A collection of myelinated fibers, comprising fibers from both the spinothalamic tract and the anterior corticospinal tract, that crosses the midline of the spinal cord immediately ventral to the gray commissure. 